\title{
Actinomyces radingae
}

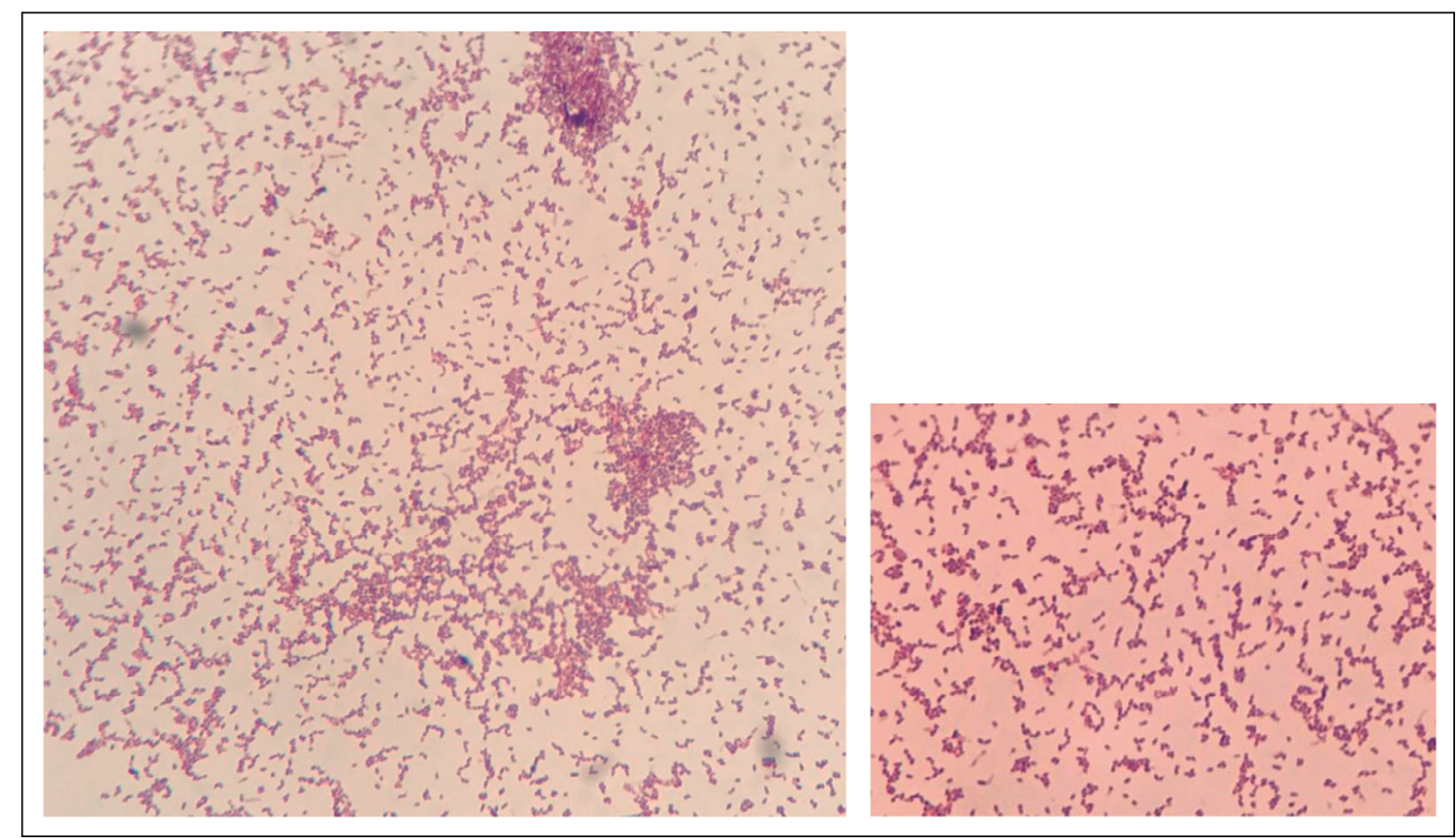

Figura 1. Tinción de Gram de Actinomyces radingae donde se observan cocobacilos grampositivos (Fotografía original de Laboratorio Microbiología Hospital San Juan de Dios).

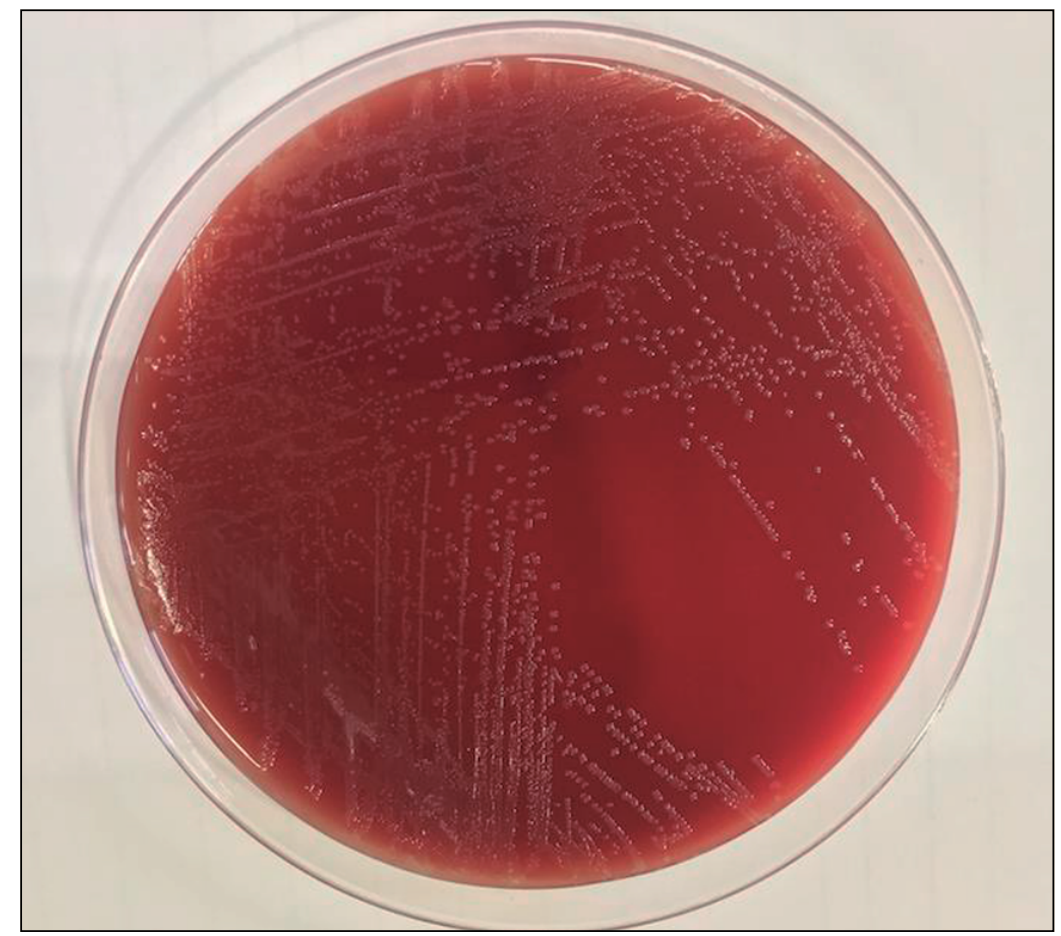

Figura 2. Cultivo en agar sangre cordero de Actinomyces radingae a las $48 \mathrm{~h}$ de incubación $5 \% \mathrm{CO}_{2}$ y $37^{\circ} \mathrm{C}$ donde se visualizan colonias grises, convexas, opacas, resplandecientes y bien delimitadas (Foto original de Laboratorio Microbiología Hospital San Juan de Dios). 


\section{Actinomyces radingae}

Actinomyces radingae fue identificado por Wüst J. y cols en 1995. Pertenece al phylum Actinobacteria, familia Actinomycetaceae y género Actinomyces. Es un microorganismo potencialmente patógeno parte de la microbiota del tracto genito-urinario y piel. Ha sido asociado a infecciones principalmente de piel y tejidos blandos, como absceso pilonidal, perineal y mamario, entre otros.

Es un cocobacilo grampositivo de $1 \mu \mathrm{m}$ de largo y $0,65 \mu \mathrm{m}$ de diámetro. Las pseudo-ramificaciones son raras, es un anaerobio facultativo; sin embargo, se desarrolla mejor en atmósfera enriquecida con $\mathrm{CO}_{2} \mathrm{o}$ en anaerobiosis. Crece bien en agar sangre de cordero y en agar chocolate. A las $48 \mathrm{~h}$ de incubación en agar sangre de cordero a $5 \% \mathrm{CO}_{2}$ y temperatura de $37^{\circ} \mathrm{C}$, se visualizan colonias pequeñas, grises, circulares convexas, opacas, resplandecientes, de consistencia butirosa y bien delimitadas, y lentamente se desarrolla una pequeña zona de $\alpha$-hemólisis. Su desarrollo es variable a $43^{\circ} \mathrm{C}$, lento a $30^{\circ} \mathrm{C} \mathrm{y}$ ausente $25^{\circ} \mathrm{C}$. De las pruebas bioquímicas convencionales destacan: catalasa, ureasa e indol negativas, no hay reducción de nitratos a nitritos, hidrólisis de la esculina positiva, en la prueba de CAMP no se detecta potenciación ni inhibición de la hemólisis. Fermentador de la maltosa y sucralosa. Presenta actividad $\alpha$-glucosidasa, $\beta$-N-acetil-glucosaminidasa y $\beta$-galactosidasa.

Actualmente, no se recomiendan los estudios bioquímicos tradicionales, dado que no permiten una identificación correcta. Se utilizan los métodos de biología molecular como el análisis de secuenciación con 16S rRNA, así como también la espectometría de masas con MALDI-TOF, que ha mostrado buen desempeño.

En general, Actinomyces spp. son susceptibles a penicilina y otros $\beta$-lactámicos así como también a la mayoría de los antimicrobianos utilizados contra los bacilos grampositivos anaeróbicos, entre ellos vancomicina; es resistente intrínsicamente a metronidazol. Se recomienda realizar estudio de susceptibilidad en caso de infecciones invasoras, pudiendo utilizarse la metodología e interpretación para bacilos grampositivos anaerobios propuestos por el CLSI y/o EUCAST mediante CIM. No obstante, la susceptibilidad para anaerobios no está disponible en la mayoría de los laboratorios de microbiología de rutina.

En conclusión, se debe sospechar la presencia de $A$. radingae en muestras de tejidos o abscesos de piel y tejidos blandos, donde se observen a la microscopia cocobacilos grampositivos, acompañados de otras bacterias de tipo anaerobios con desarrollo de colonias puras catalasa negativa en ambiente aeróbico.

\section{Referencias bibliográficas}

1.- Könönen E, Wade W G. Actinomyces and related organisms in human infections. Clin Microbiol Rev 2015; 28: 419-42. doi: 10.1128/ CMR.00100-14.

2.- Hall V, Copsey S. Propionibacterium, Lactobacillus, Actinomyces, and Other Non-Spore-Forming Anaerobic Gram-Positive Rods. En Jorgensen J, Pfaller M, Carroll K, Funke G, Landry M, Richter S, Warnock D (Ed.), Manual of Clinical Microbiology, $11^{\text {th }}$ Edition. ASM Press, Washington, DC. 2015; p 920-939. doi: 10.1128/9781555817381.ch52.

3.- Vandamme P, Falsen E, Vancanneyt M, Van Esbroeck M, Van de Merwe D, Bergmans A, et al. Characterization of Actinomyces turicensis and Actinomyces radingae strains from human clinical samples. Int J Syst Bacteriol 1998; 48: 503-10.

4.- Sabbe L, Van De Merwe D, Schouls L, Bergmans A, Vaneechoutte M, Vandamme P. Clinical spectrum of infections due to the newly described Actinomyces species A. turicensis, A. radingae, and A. europaeus. J Clin Microbiol 1999; 37: 8-13.

5.- Hoogewerf M, Diepenhorst G, Visser H, Peters E, van Dijk K. A breast abscess caused by Actinomyces radingae. J Microbiol Infect Dis 2016; 6 (2): 84-86. doi: 10.5799/ahinjs.02.2016.02.0222. 